\title{
Bacillus anthracis: \\ Una larga historia de terror
}

\author{
WALTER LEDERMANN D.
}

Bacillus anthracis: a long history of terror

Publio Virgilio Marón, a despecho de lo que sugiere su nombre de futbolista argentino, fue uno de los mayores poetas en la historia de Occidente. Nacido en Andes, Mantua, el año 70 A.C. alcanzó la inmortalidad al escribir La Eneida, ubicándose de golpe a la vera de Homero y mereciendo siglos más tarde el honor de guiar al Dante en su viaje imaginario de La Divina Comedia. Sin embargo, este poeta épico tenía también una porción de inspiración "rural", que lo llevó a escribir las Bucólicas y las Geórgicas, donde trata temas campesinos. En el libro tercero de estas últimas, describe con cierta prolijidad las enfermedades del ganado, narrando cómo

"Manadas enteras por la peste mueren

$y$ hasta en los mismos establos

se hacinan los cadáveres destrozados

con la horrible infección

Forzoso se hace cubrirlos de tierra

y sepultarlos en profundas hoyas

que ni pueden sus pieles servir para nada,

ni medio alguno de limpiar sus carnes

ni con agua ni con fuego,

ni siquiera urdir sus vellones

por la atroz podredumbre carcomidos,

ni asir con mano leve

aquellas lanas apestadas,

pues si alguno probaba a vestirse

con aquellos despojos repugnantes,

al punto se le cubría

el cuerpo de ardientes postillas"... ${ }^{1}$

La peste parece corresponder al "carbón" descrito por Hipócrates (¿qué no describió ese hombre?) en el siglo $\mathrm{VAC}^{2}$, aunque el poeta no lo menciona explícitamente. También se dice que Homero se habría referido al carbunco en La Ilíada, pero debe haberlo hecho en forma muy metafórica, pues no hemos podido encontrarlo en canto alguno, y la descripción que hace de la mortandad desencadenada por la cólera de Apolo difícilmente puede atribuirse al Bacillus anthracis, ya que las flechas del irritado dios mataron primero a "los mulos y los veloces perros $^{\prime \prime}$, siendo estos últimos refractarios al carbunco. Siempre en el terreno de la mitología, nárrase que la túnica con que la celosa Deyanira arropó al esquivo Hércules, causándole la muerte, contamina- da estaba con la piel peluda del centauro Neso. Esta historia plantea un problema infectológico interesante, pues si bien Neso, mitad hombre, mitad caballo, pudo albergar al ántrax en su porción equina, habría sido Hércules, en primer término, quien lo infectara con flechas envenadas: si lo estaban con esporas, eso haría al mítico guerrero precursor del terrorismo y víctima, a la vez, del mismo, ya que el centauro impregnó su túnica - y no su piel -con sangre carbuncosa, entregándola a la celosa Deyanira para su criminal atentado 4 .

Una descripción más "científica" del carbunco la encontramos en De medicina, del misterioso médico romano Aurelio Cornelio Celso, quien, hablando de las lesiones de causas externas, dice: De éstas, no hay otra más grave que el carbunclo, cuyas notas características son las siguientes: el punto afectado presenta rubicundez y pústulas poco prominentes y negras... 5

Antrax es el término griego para carbón y carbunclo el latino, éste derivado de carbunculus, que significa rubí: poéticamente, el carbón que arde en la oscuridad. Y, después del once de septiembre...i vaya que arde! Pero lo cierto es que su etiología permaneció en la oscuridad hasta 1850, aunque en la parte clínica hubo serios intentos para sistematizar su estudio, llegando la Academia de Dijon en 1780, luego de terribles epidemias de pústula maligna en el ganado francés, con los consecuentes casos humanos, a llamar a un concurso de Mémoires, que permitió establecer tres grados de compromiso: a) carbón interno o fiebre carbuncosa, sin manifestaciones cutáneas, b) carbón esencial, sin pródromos, c) carbón sintomático, con fiebre, pródomos y tumeurs gazeuses (¿edema?) ${ }^{6}$.

Pero vayamos a 1850 , cuando el médico francés Casimir Joseph Davaine (1812-1882), cuyo nombre no pudo ser inmortalizado por el carbunclo, pero sí por los Davaineidaea, un familia de gusanos céstodos que parasitan aves y mamíferos ${ }^{7}$, vio en la sangre de animales carbuncosos des petits corps filiformes, ayant environ le double de longeur d'un globule sanguin: les battonets ou baguettes du charbon. También Rayer vio los bastoncitos en similares circunstancias, en ese mismo año cincuenta $\mathrm{y}$, al parecer, un poco antes que Davaine, con quien comparte el descubrimiento ${ }^{8}$. 
A raíz de estos informes, la Asociación Médica y la Sociedad Veterinaria de Eure y Loir comenzaron una serie de trabajos que llevaron a establecer la unidad de las patologías conocidas como "sangre del bazo del cordero", "fiebre carbonosa del caballo", "enfermedad de la sangre de vaca" y "pústula maligna del hombre", demostrando también su trasmisión al conejo y la persistencia del agente causal en los animales muertos.

Sin embargo, 26 años habrían de transcurrir desde las observaciones de Davaine y Rayer hasta el aislamiento del bacilo carbuncoso por Robert Koch. En 1857 puede que haya sido visto también por Brauell, un veterinario que hacía clases en la Escuela Veterinaria de Dorpat, pero éste terminó por confundirlo con el Clostridium septicum.. Tres años después nos topamos con la figura ligeramente trágica del veterinario Roger Delafond, hombre estudioso pero desafortunado. Una misteriosa epizootia diezmaba a los caballos de la Compagnie des Petites Voitures de Paris, llevándola al borde de la quiebra $\mathrm{y}$ forzando a sus ejecutivos a llamar a un experto, con todo el riesgo que ello suele implicar... Este experto era Delafond, quien de inmediato hizo el diagnóstico de carbunco, pero no contento con esta sola conclusión, quiso demostrar a los empresarios el mecanismo de diseminación de esta peste, procediendo a inocular un cordero con la sangre de un caballo infectado. De este modo logró trasmitir el carbunco y, de paso, cultivar las baguettes, concluyendo que pertenecían al reino vegetal. Estos descubrimientos fueron acogidos en forma más que sarcástica por sus colegas del mundo científico de la época, quienes lo abrumaron con sus burlas, impidiéndole acreditar su descubrimiento9.

Davaine fue la excepción y, lejos de sumarse a las carcajadas, cotejó los hallazgos del infortunado Delafond con la memoria de Pasteur sobre la fermentación butírica, planteando luego que estos bastoncitos, "fermentando" en la sangre, causaban la enfermedad. Para probar su afirmación debió luchar diez años contra encendidos adversarios, entre ellos los profesores de Val-de-Grace Jaillard y Leplat, quienes inocularon a mort varios conejos con sangre de animales muertos por carbunclo, sin encontrar en los conejos bastoncito alguno9. En 1875 Signol terminó por abatirlo al asfixiar animales sanos, absolutamente ajenos al carbón, para encontrar en ellos, seis horas después, los famosos bastoncitos en su sangre coagulada ${ }^{10}$. Así se perdió Davaine la autoría, pues el mismo año logró Koch cultivar el bacilo con la técnica de gota colgante en humor acuoso (iqué ojo tuvo!). Y no sólo cultivarlo, sino de describir el ciclo de bacilo-espora-bacilo completo ${ }^{11}$.

Aquí monta Koch en el brioso corcel de su talento, levanta su lanza y carga contra los enemigos de Davaine, haciéndoles morder el polvo. Empieza por demostrar los errores en las experiencias de Jaillard y Leplat, quienes en realidad habrían inoculado sus conejos "con otro virus". Pulverizados éstos, arremete contra Signol, asfixiando caballos sanísimos y recuperando de sus cadáveres ese "otro virus". ¿Y cuál era ese otro virus, "largo, translúcido, flexuoso y móvil, rampant entre les globules sanguins comme un serpent dans l'herbe" ? ¿Sería, Koch, de paso y también, poeta?). El "otro virus" era un "vibrión séptico", probablemente el Clostridium septicum o el Clostridium chauvoei ${ }^{12}$.

Uno podría creer que el descubrimiento de Koch cambió radicalmente la conducta en el manejo del carbunclo y salvó muchas vidas, pero no fue así, porque las malas costumbres difícilmente se erradican y el negocio impera con frecuencia sobre la razón. Para entenderlo, basta un párrafo de un texto de higiene del año del descubrimiento ${ }^{13}$, que en lugar de prohibir el trabajo con pieles de animales infectados, entrega las más inútiles y peligrosas recomendaciones a los curtidores: Se tomarán las mayores precauciones en la manipulación de pieles carbuncosas. Los talleres serán ventilados de la manera más completa... una ventilación actuando de arriba hacia abajo será rigurosamente aplicada. Se recomienda el uso de máscaras enrejadas... ( $\mathrm{Y}$ el bacilo se reía a carcajadas).

Treinta años después de conocido que el carbunco era causado por un bacilo esporulado, transmisible por productos de animales fallecidos de la enfermedad, en 1906, Debray publica una estadística de 247.000 casos reunidos en la Dirección de la Oficina del Trabajo de Francia ${ }^{14}$, mostrando una espantable mortalidad profesional, absolutamente evitable, que se distribuía de esta manera entre las "profesiones de riesgo":

$\begin{array}{lr}\text { Carniceros al detalle } & 36,4 \% \\ \text { Tapiceros y ebanistas } & 18,0 \% \\ \text { Silleros (de montar ) } & 14,8 \% \\ \text { Curtidores } & 8,0 \% \\ \text { Pastores } & 6,4 \% \\ \text { Cosedores de guantes de piel } & 4,9 \%\end{array}$

¿Cabe asombrarse de la estulticia de nuestros congéneres de hace un siglo cuando, entrando en el tercer milenio, debemos agregar a esta lista de oficios peligrosos a los carteros y otras personadas relacionadas con el correo, que ya tienen una docena de afectados en EE.UU.? ${ }^{15}$ Aquellas víctimas de un siglo atrás sabían que manipulaban material infectado, con un bacilo carbuncoso que seguía los caminos epidemiológicos de la naturaleza, pero los de ahora se exponen sin saberlo a bacilos que siguen los tortuosos caminos de la maldad humana.

Al descubrimiento de Koch siguieron numerosos otros, relativos a la espora, a la cápsula, a la resistencia a desinfectantes y calor, etc, de las cuales unas pocas citaremos de una antigua revisión de Eurich y Hewlett ${ }^{16}$. Una se refiere al hallazgo de la toxina por Marmier, quien, siguiendo estudios preliminares pero inconsistentes de Hankin, Baerger y Fraenkel, pudo extraer de los cultivos, en 1895, un polvo café, soluble en agua, muy tóxico para los animales sensibles al carbunco: conejo, cobayo, ratón, pero inactivo frente a los refractarios, que determinaba un estado febril, con diarrea y caquexia, seguido de caída de la temperatura y curación, o de paraplejía y muerte entre convulsiones, y que hoy 
sabemos mediada por el plasmidio pXO 1, con factores de edema y de letalidad.

La cápsula. El otro factor de virulencia, fue descrita por Pianèse y Kern, logrando Johne un precioso método de tinción para ponerla en evidencia. Hoy sabemos que un segundo plasmidio pXO 2 es el culpable de este mecanismo agresivo del $B$. anthracis.

¿Y Pasteur? Aparte de un ardoroso encuentro con Koch, su tradicional rival, donde el francés sostenía que los gusanos llevaban las esporas desde los cadáveres sepultados hasta la superficie de la tierra, y el alemán se burlaba, afirmando que la tierra se contaminaba con deposiciones y orina de los animales vivos, el padre de la bacteriología protagonizó dos experiencias célebres. La primera fue el famoso enfriamiento de las patas de los pollos, demostrando como estas aves, naturalmente refractarias al carbunco, contraían la mortal enfermedad al bajarles así la temperatura corporal de 42 a $38^{\circ} \mathrm{C}$. Cultivando luego los bacilos a $42^{\circ} \mathrm{C}$ inició sus trabajos para conseguir una cepa avirulenta, utilizable como vacuna. Con esto obtuvo una cepa atenuada, pero incapaz de esporular, a menos que la recultivara a $35^{\circ} \mathrm{C}$. Eureka: hízolo así el sabio y logró una cepa avirulenta capaz de esporular ${ }^{17}$.

A iniciativa del veterinario Rossignol, la Sociedad de Agricultura de Melun, presidida por el filántropo barón De la Rochette, auspició y financió el proyecto de vacunación'. El 5 de mayo de 1881 se reunió en Poully-le-Fort una muchedumbre de veterinarios, médicos, agricultores, funcionarios, periodistas, etc, a presenciar cómo Pasteur vacunaba 24 ovejas, 1 cabra y 6 vacas, aunque los franceses Arloing y Thévenot sostienen que fueron 60 corderos $^{9}$. La segunda dosis fue el 17 de mayo, ahora con menos público. La mayor asistencia habría de lograrse el 31 de Mayo, día del challenge, para presenciar cómo Pasteur manipulaba sus tubos con los mortíferos bacilos.

-¡Momento! -gritó Colin, tenaz contradictor de Pasteur.- ¡Exijo que se agiten los tubos, para que los bacilos no se queden en el fondo!

-Comme vous voulez -respondió el maestro, sacudiéndolos vivement et avec rage.

Nada pasó ese día. El 5 de junio la experiencia terminó: los sesenta corderos vacunados estaban vivos, mientras habían muerto todos los controles, constituidos por 24 ovejas, 1 cabra y 4 vacas $^{18}$. ¿Éxito indiscutible? Koch pensaba que no, y contraatacó al año siguiente, con una gruesa publicación crítica y destructiva. Pasteur demandó una discusión pública y encontró la ocasión en el Congreso Internacional de Higiene, en Génova, donde se topó con el germano ${ }^{19}$.

- Je voudrais bien discuter avec vous...-empezó el francés. dose.

- ¡Ich, nicht! -replicó fríamente el alemán, aleján-

Dejemos a estos peleadores y digamos algo sobre el tratamiento. En 1910 Becker ensayó el famoso salvarsan, un arsenical utilizado en la sífilis ${ }^{20}$. En la década de los treintas se probaron diversas sulfamidas, con relativo éxito ${ }^{21}$. En 1939 el mismísimo Fleming encontró que la penicilina era activa in vitro, empleándola F.D. Murphy como tratamiento triunfal en $1944^{22}$. Hasta entonces, el éxito se confiaba a una dudosa y cruel sueroterapia y a algunos pintorescos ensayos con piocianasa, el pigmento azul de Pseudomonas aeruginosa, la especie que con mayor facilidad mata al Bacillus anthracis en el laboratorio. Alentado por este antagonismo in vitro, en 1914 los Fortinaeu trataron 50 pacientes humanos con cultivos muertos que contenían piocianasa, con una mortalidad de $10 \%{ }^{23}$, lo cual, comenta con cierta gracia Eurich, quien prefería el salvarsan, was not a very satisfactory result ${ }^{16}$. Los franceses, por su parte, hablaron des observations favorables: ils (los Fortineau) n'ont eu que cinq décès sur cinquante cas, et toujours dans des formes très graves... ${ }^{9} \mathrm{Oh}$, estas rivalidades étnicas!

Terminemos con una curiosa noticia de nuestros días. En 1947, el futuro Presidente de EE.UU. Ronald Reagan, recordado por la energía con que combatió al terrorismo, protagonizó el film Valle del sol, donde personificaba al veterinario Larry Hanrahan, quien descubría una vacuna contra el ántrax, prohibida luego por el gobierno... ${ }^{24}$ ¿Logrará el Presidente Bush en la realidad lo que su predecesor lograba en la ficción: vencer al Bacillus anthracis? Siguiendo con el cine, confiemos en los hombres del presidente.

\section{Bibliografía}

1.- Virgilio. La Eneida, seguida de Bucólicas y Geórgicas. Editorial Iberia S.A., Barcelona 1959; pp. 384-7.

2.- Chadwick J, Mann W. N. Hippocrates Corpus. Blackwell Sc. Pub., Oxford 1950.

3.- Homero. La Iliada. Editorial Iberia S.A., Barcelona 1960; p. 4.

4.- Duckworth G E, Rose H L. Heracles. En: Collier's Encyclopedia. Crowell Collier and Mac Millan, inc., USA 1967; 12: 54-5.

5.- Celso A C. Los 8 libros de la medicina. Editorial Iberia S.A., Barcelona 1966; II 9: 66-7.

6.- Academie De Dijon. On étude au concours sur le charbon et couronne les mémoires de Tomassin, Chambon et Saucerotte. Annales de l'Academie, DijonFrance 1786; II.

7.- Dorland's Illustrated Medical Dictionary. 28th edition. W.B.Saunders Company, Phi.,1994; p. 429

8.- RAYER P. Premier rapport. C.R. Soc Biol París 1850; 2: 141-7.

9.- Arloing F, Thévenot L. Charbon. En: Debré R et Aubry G. Maladies infectieuses et parasitaires. 1re.éd., 18 Rue Séguier, Paris 1935; 8034: 1-12.

10.- De Saint-Martin. Recherches experimentales sur la respiration. Octave Doin, Ëditeur, 8 Place del'Odéon, Paris 1893; pp. 219-29.

11.- Koch R. Die Ätiologie der Milzbrand. Beitr Biol Pfl 1877; II, Heft 2: 277.

12.- Bulloch W. Bacillus anthracis. En :Medical Research Council. A system of Bacteriology in relation to Medicine. His Majesty's Stationery Office, London 1930; I: 67.

13.- Layet A. Hygiène des professions et des industries précedée d'une étude générale des moyens de prévenir 
et de combattre les effets nuisibles de tout travail professionel. Librairie J.B. Baillière et fils, Rue Hautefeuille, Paris, 1875; 19: pp. 450-1.

14.- Debray M. Statisque d'hygiène des professions publiée à la Direction de l'Office du Travail. Soc Biol Paris 1906; 59: 911-8.

15.- Update: Investigation of bioterrorism-related anthrax and interim guidelines for clinical e of persons with possible anthrax. MMWR Nov 2, 2001; 50 (43): 94414.

16.- Eurich F W, Hewlett R T. Bacillus anthracis. En: Medical Research Council. A system of Bacteriology in relation to Medicine. His majesty's Stationery Office, London 1930; 5: 439-78.

17.- Pasteur L. Etudes sur la virulence du charbon. CR Acad Sci Paris 1881; 92: 429-35; ibid 666-80; ibid 1378-83.

18.- Ledingham J C G, Schütze H L. The production of active immunity to bacterial and virus infections of man and animals. En: Medical Research Council. A system of Bacteriology in relation to Medicine. His Majesty's Stationery Office, London 1930; 6: 80-81.

19.- Gosio B. Roberto Koch e la sua opera. Il Policlinico 1910; 17: 285

20.- Eurich F W. Salvarsan in anthrax. J Path Bact 1912; 17: 249.

21.- Ravina A. Traitement du charbon par les sulfamides. Presse Méd 1940; 17 (20): 424-9.

22.- Murphy F D, La Boccetta A G, Lockwood J S. Traitement d'un anthrax humain par la pénicilline. JAMA 1944; 126: 948-50.

23.- Fotineau L, Fotineau C. Traitement du charbon avec pyocianase. C.R. Acad Sci Paris 1914; 158: 1035.

24.- Ronald Reagan combatió el ántrax en 1947. El Mercurio, Santiago, 2001 (Noviembre 12); C 15. 